\title{
100. Measurement of large amplitude plane vibrations of two dimensional structures
}

\author{
V. Maskeliūnas', R. Maskeliūnas², A. Pauliukas³, L. Ragulskis ${ }^{4}$ \\ ${ }^{1}$ Vilnius Gediminas Technical University, Vilnius, Lithuania \\ ${ }^{2}$ Vilnius University, Vilnius, Lithuania \\ ${ }^{3}$ Aleksandras Stulginskis University, Akademija, Kaunas District, Lithuania \\ ${ }^{4}$ Vytautas Magnus University, Kaunas, Lithuania \\ ${ }^{2}$ Corresponding author \\ E-mail: ${ }^{1}$ vytautas.maskeliunas@stud.vgtu.lt, ${ }^{2}$ rimas.maskeliunas@gmail.com, ${ }^{3}$ arvydas.pauliukas@asu.lt, \\ ${ }^{4}$ l.ragulskis@if.vdu.lt
}

Received 1 June 2016; received in revised form 4 August 2016; accepted 11 August 2016 DOI http://dx.doi.org/10.21595/jme.2016.17543

\begin{abstract}
In the paper large amplitude plane vibrations of an elastic structure are investigated experimentally by using the method of time averaged geometric moiré. Investigations of a two-dimensional problem are performed. Experimental setup is developed and the results obtained by using the experimental procedure are analyzed. On the basis of a one-dimensional model graphical relationships for linear variation with respect to longitudinal coordinate of amplitude of vibrations are obtained. They provide the background for interpretation of partially exposed time averaged moiré. Recommendations for the choice of background intensity are provided.
\end{abstract}

Keywords: two-dimensional structure, elastic structure, plane vibrations, large amplitude vibrations, time averaged moiré, geometric moiré, experimental setup, experimental results, background intensity.

\section{Introduction}

In the paper large amplitude plane vibrations of an elastic structure are investigated experimentally by using the method of time averaged geometric moiré. Investigations of a two-dimensional problem are performed. Experimental setup is developed and the results obtained by using the experimental procedure are analyzed. On the basis of a one-dimensional model graphical relationships for linear variation with respect to longitudinal coordinate of amplitude of vibrations are obtained. They provide the background for interpretation of partially exposed time averaged moiré. Recommendations for the choice of background intensity are provided.

This paper continues the analysis of time averaged moiré techniques presented in [1]. Similar problems are analyzed in [2-17] and in a number of other similar papers.

\section{Experimental measurements of large amplitude vibrations}

The investigated elastic structure with moiré lines attached to the vibroexciter is shown in Fig. 1.

Experimental time averaged image is shown in Fig. 2.

Part of the zoomed image of Fig. 2 is shown in Fig. 3. Time averaged moiré lines for large amplitude vibrations are seen in it.

This image shows that partially exposed moiré lines can be used for the measurement of large amplitude vibrations. 


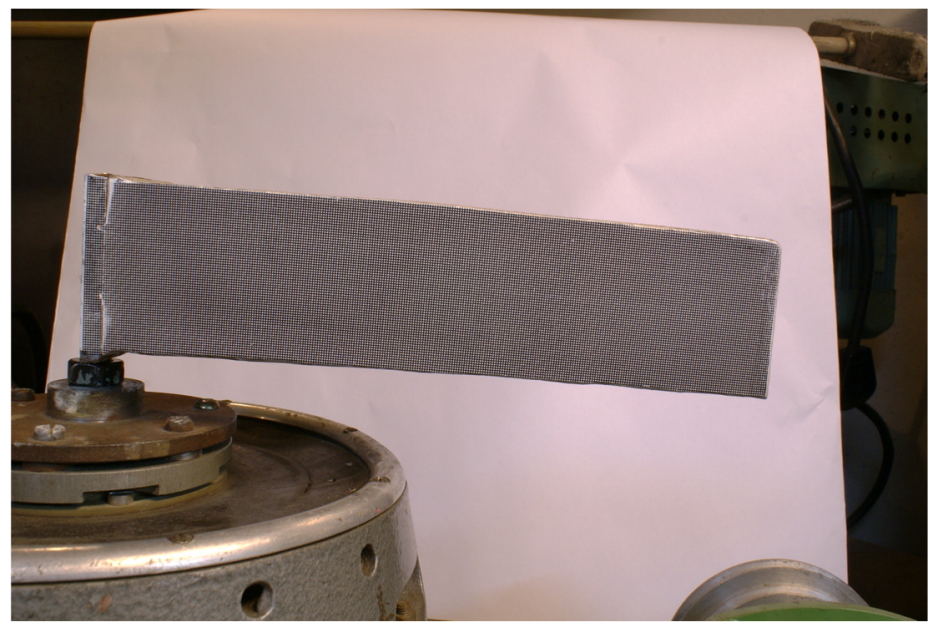

Fig. 1. The investigated elastic structure with moiré lines attached to the vibroexciter

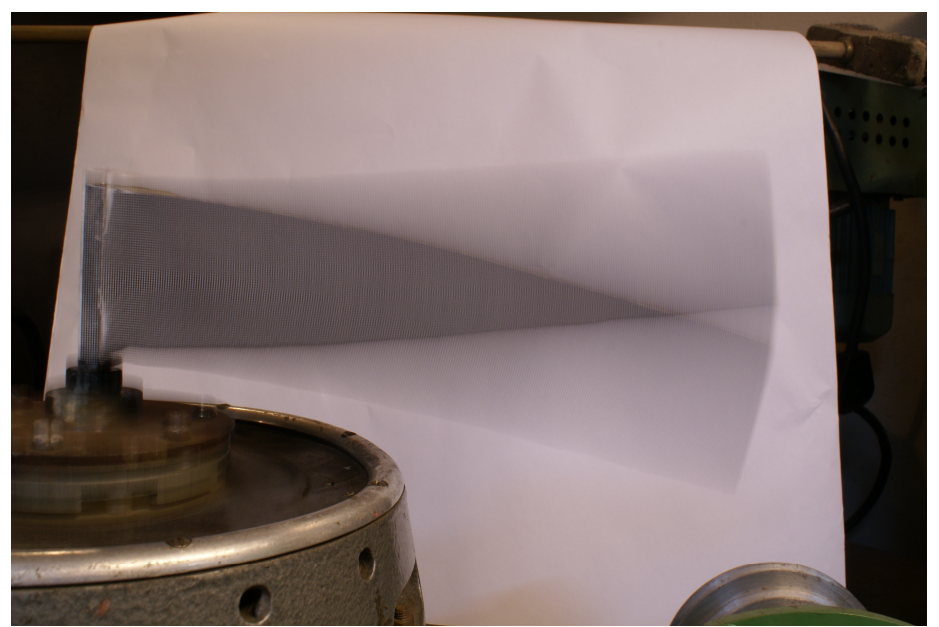

Fig. 2. Experimental time averaged image for frequency of excitation $9 \mathrm{~Hz}$

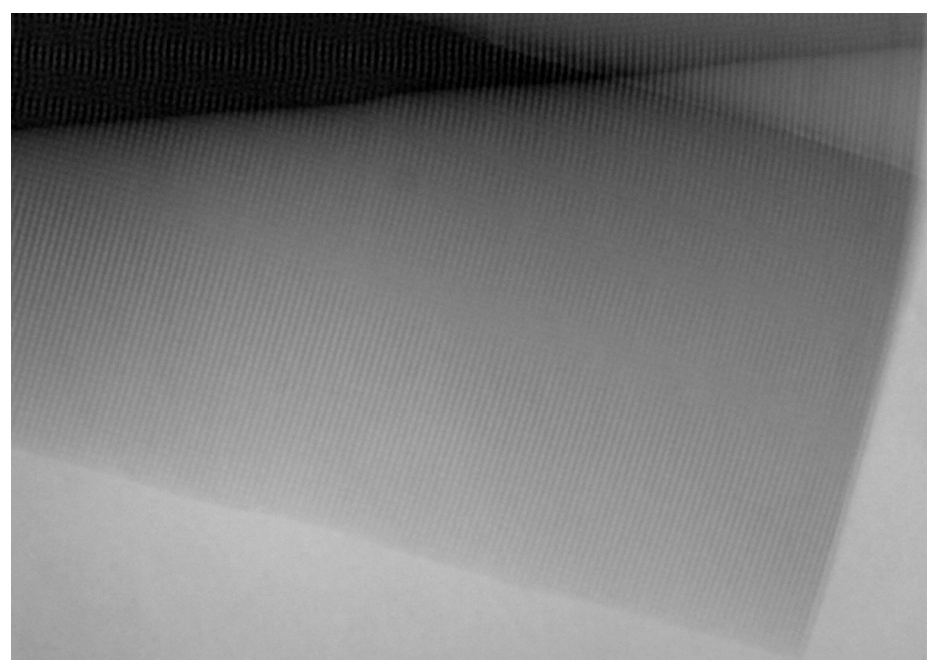

Fig. 3. Part of the zoomed image of Fig. 2 


\section{Theoretical investigation of the time averaged partially exposed measurement of vibrations}

This investigation is based on the use of the one-dimensional model.

Intensity of the time averaged partially exposed image is represented as:

$\bar{I}_{b}=\frac{1}{m} \sum_{j=1}^{m}\left\{\begin{array}{l}b, \quad\left|\theta_{j}\right|>\theta, \\ \cos ^{2} \frac{\pi}{\lambda}(x-u), \quad\left|\theta_{j}\right| \leq \theta,\end{array}\right.$

where $\bar{I}_{b}$ is the intensity of the time averaged partially exposed image, $m$ is a large integer number, $b$ is the background intensity, $\theta$ is the cutting parameter, $\lambda$ determines the width of moire lines, $x$ is the coordinate of a point of a one-dimensional structure in the status of equilibrium, $u$ is the displacement and:

$\theta_{j}=-\pi+2 \pi \frac{j-\frac{1}{2}}{m}$

and it is assumed that:

$u=k x \cos \theta_{j}$,

where $k$ is a constant.

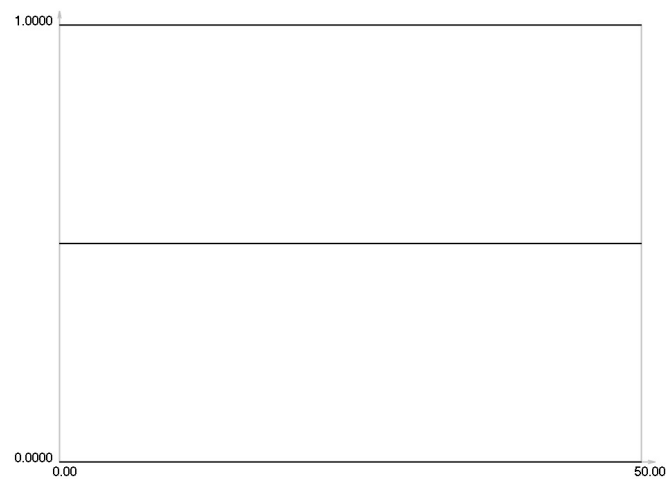

Fig. 4. $\bar{I}_{0}, \bar{I}_{1 / 2}$ and $\bar{I}_{1}$ when $\theta=0 \cdot \pi / 4$

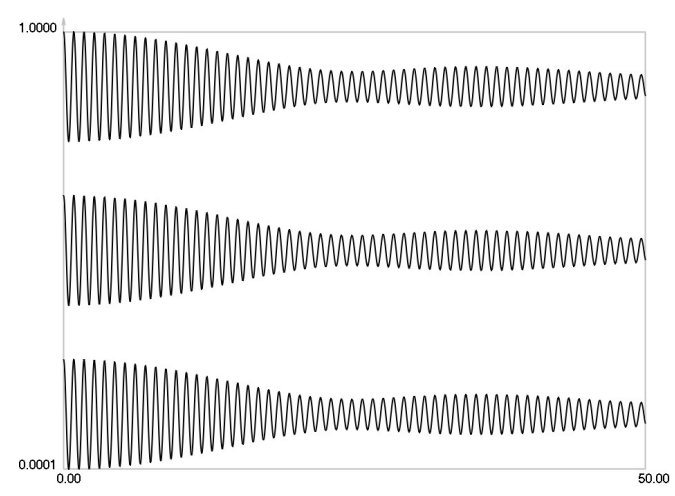

Fig. 5. $\bar{I}_{0}, \bar{I}_{1 / 2}$ and $\bar{I}_{1}$ when $\theta=1 \cdot \pi / 4$

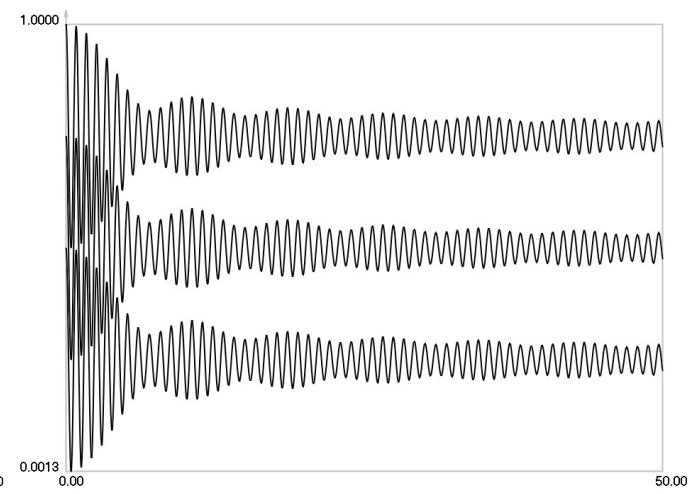

Fig. 6. $\bar{I}_{0}, \bar{I}_{1 / 2}$ and $\bar{I}_{1}$ when $\theta=2 \cdot \pi / 4$ 


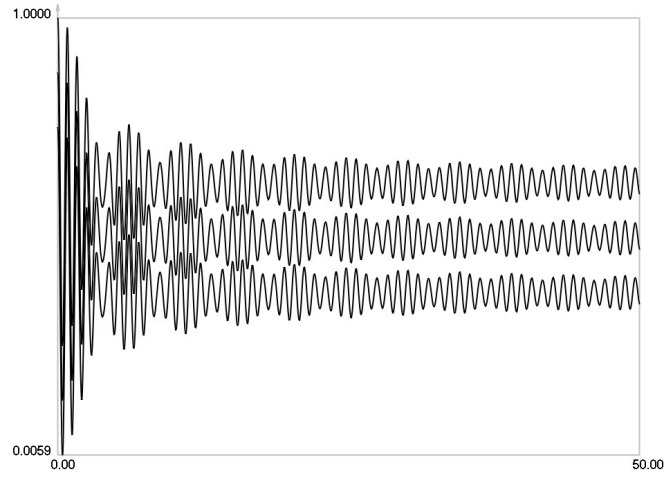

Fig. 7. $\bar{I}_{0}, \bar{I}_{1 / 2}$ and $\bar{I}_{1}$ when $\theta=3 \cdot \pi / 4$

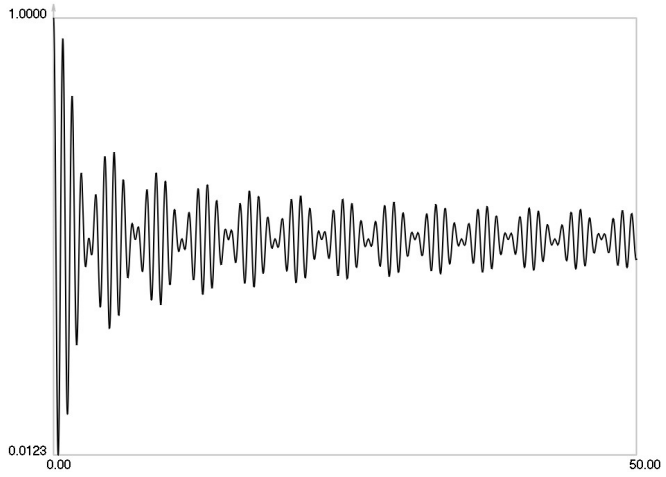

Fig. 8. $\bar{I}_{0}, \bar{I}_{1 / 2}$ and $\bar{I}_{1}$ when $\theta=4 \cdot \pi / 4$

In the performed investigation parameters have the values: $\lambda=0.8$ and $k=0.1$.

$\bar{I}_{0}, \bar{I}_{1 / 2}$ and $\bar{I}_{1}$ when $\theta=0 \cdot \pi / 4$ are graphically shown in Fig. 4.

$\bar{I}_{0}, \bar{I}_{1 / 2}$ and $\bar{I}_{1}$ when $\theta=1 \cdot \pi / 4$ are graphically shown in Fig. 5.

$\bar{I}_{0}, \bar{I}_{1 / 2}$ and $\bar{I}_{1}$ when $\theta=2 \cdot \pi / 4$ are graphically shown in Fig. 6.

$\bar{I}_{0}, \bar{I}_{1 / 2}$ and $\bar{I}_{1}$ when $\theta=3 \cdot \pi / 4$ are graphically shown in Fig. 7.

$\bar{I}_{0}, \bar{I}_{1 / 2}$ and $\bar{I}_{1}$ when $\theta=4 \cdot \pi / 4$ are graphically shown in Fig. 8.

For conventional time averaged moiré, the envelope function has the form:

$E(u)=\frac{1}{2} \pm \frac{1}{2} J_{0}\left(\frac{2 \pi}{\lambda} u\right)$

where $J_{0}$ is the zero order Bessel function of the first kind.

For partially exposed time averaged moiré the envelope function has the form:

$E(u, \theta, b)=\frac{1}{2} \pm \frac{1}{2} \bar{J}_{0}\left(\frac{2 \pi}{\lambda} u, \theta, b\right)$

where $\bar{J}_{0}$ is the modified zero order Bessel function of the first kind, $\theta$ is the cutting parameter, $b$ is the background parameter.

From the presented graphical relationships qualities of the modified zero order Bessel function of the first kind are seen. They enable to interpret partially exposed time averaged moiré images.

From the presented results it is recommended to choose the background intensity as:

$b=\frac{1}{2}$

This has the advantage in the interpretation of experimental results because the intensity values are not shifted towards black or white.

\section{Conclusions}

Large amplitude plane vibrations of an elastic structure are investigated experimentally. Experimental setup is developed and the results obtained by using the experimental procedure are analyzed. On the basis of obtained experimental results it is shown that partially exposed moiré lines can be used for the measurement of large amplitude vibrations.

On the basis of a one-dimensional model graphical relationships for linear variation with respect to longitudinal coordinate of amplitude of vibrations are obtained. They provide the background for interpretation of partially exposed time averaged moiré. 
From the presented graphical relationships qualities of the modified zero order Bessel function of the first kind are seen. They enable to interpret partially exposed time averaged moiré images.

From the presented results it is recommended to choose the background intensity as grey color exactly in the middle between black and white. This has the advantage in the interpretation of experimental results because the intensity values are not shifted towards black or white.

The obtained results are used for the analysis and measurement of large amplitude vibrations of mechanical devices, especially when high precision is required.

\section{Acknowledgements}

The authors thank the reviewers for their valuable comments. They enabled to improve the paper.

\section{References}

[1] Ragulskis M., Maskeliūnas R., Ragulskis L., Turla V. Investigation of dynamic displacements of lithographic press rubber roller by time average geometric moiré. Optics and Lasers in Engineering, Vol. 43, 2005, p. 951-962.

[2] Maskeliūnas R., Ragulskis K., Paškevičius P., Patašienė L., Ragulskis L. Superimposed moiré measurements of vibrations of circular structures. Journal of Measurements in Engineering, Vol. 4, Issue 1, 2016, p. 15-22.

[3] Maskeliūnas R., Ragulskis K., Paškevičius P., Pauliukas A., Ragulskis L. Selection of number of gaps in superimposed moiré measurements. Journal of Measurements in Engineering, Vol. 3, Issue 4, 2015, p. 138-144.

[4] Ragulskis M., Maskeliūnas R., Ragulskis L. Plotting moiré fringes for circular structures from FEM results. Experimental Techniques, Vol. 26, Issue 1, 2002, p. 31-35.

[5] Maskeliūnas R., Ragulskis K., Paškevičius P., Patašienė L., Pauliukas A., Ragulskis L. Measurement of plane vibrations of a two-dimensional elastic structure. Journal of Measurements in Engineering, Vol. 3, Issue 2, 2015, p. 42-47.

[6] Ragulskis K., Maskeliūnas R., Zubavičius L. Analysis of structural vibrations using time averaged shadow moiré. Journal of Vibroengineering, Vol. 8, Issue 3, 2006, p. 26-29.

[7] Saunorienè L., Ragulskis M. Time - Averaged Moiré Fringes. Lambert Academic Publishing, 2010.

[8] Huimin X., Guotao W., Fulong D., Guangjun Z., Xingfu L., Fangju Z., Aiming X. The dynamic deformation measurement of the high speed heated LY12 aluminium plate with moiré interferometry. Journal of Materials Processing Technology, Vol. 83, Issues 1-3, 1998, p. 159-163.

[9] Deason V. A., Epstein J. S., Abdallah A. Dynamic diffraction moiré: theory and applications. Optics and Lasers in Engineering, Vol. 12, Issues 2-3, 1990, p. 173-187.

[10] Kokaly M. T., Lee J., Kobayashi A. S. Moiré interferometry for dynamic fracture study. Optics and Lasers in Engineering, Vol. 40, Issue 4, 2003, p. 231-247.

[11] Timoshenko S. P., Goodier J. N. Theory of Elasticity. Nauka, Moscow, 1975.

[12] Soifer V. A. Computer processing of images. Herald of the Russian Academy of Sciences, Vol. 71, Issue 2, 2001, p. 119-129.

[13] Vest C. Holographic Interferometry. Mir, Moscow, 1982.

[14] Han B., Post D., Ifju P. Moiré interferometry for engineering mechanics: current practices and future developments. Journal of Strain Analysis for Engineering Design, Vol. 36, Issue 1, 2001, p. 101-117.

[15] Field J. E., Walley S. M., Proud W. G., Goldrein H. T., Siviour C. R. Review of experimental techniques for high rate deformation and shock studies. International Journal of Impact Engineering, Vol. 30, Issue 7, 2004, p. 725-775.

[16] Dai F. L., Wang Z. Y. Geometric micron moiré. Optics and Lasers in Engineering, Vol. 31, Issue 3, 1999, p. 191-198.

[17] Liang C. Y., Hung Y. Y., Durelli A. J., Hovanesian J. D. Time-averaged moiré method for in-plane vibration analysis. Journal of Sound and Vibration, Vol. 62, Issue 2, 1979, p. 267-275. 